\title{
Investigation on Porosity and Microstructure of Molecular Sieve Wick Heat Pipe
}

\author{
LPI Midiani ${ }^{1}$, IWA Subagia ${ }^{2}$, IBG Widiantara ${ }^{3}$ \\ Mechanical Engineering \\ Bali State Polytechnic \\ Badung, Indonesia \\ 1putuikemidiani@pnb.ac.id
}

\author{
WN Septiadi ${ }^{4}$, INS Winaya ${ }^{5}$, M. Sucipta ${ }^{6}$ \\ Mechanical Engineering \\ Udayana University \\ Badung, Indonesia
}

\author{
N Putra ${ }^{7}$ \\ Departement of Mechanical Engineering \\ University of Indonesia \\ Depok, Indonesia
}

\begin{abstract}
Wick must provide in order that heat pipe can be operate in any orientation. Wick provide the driving forces to circulate working fluids. A novel sintered molecular sieve and hybrid molecular sieve-Cu would be use as wick heat pipe. This paper presents the results of investigation on porosity and microstructure of molecular sieve. Physical properties of the molecular sieve such as porosity and microstructure will measured and evaluated. Porosity and microstructure of molecular sieve would affect capillary force of the wick, hence affect the performance of heat pipe. Several properties that influence the performance of wick heat pipe are capillary force, permeability, wettability and thermal conductivity. The preparation step was achieved by made wick sample. Two kind of particle size i.e. $100 \mu \mathrm{m}$ and $200 \mu \mathrm{m}$ and made into slurry. The slurry was shaped in the form of copper pipe in 1 inch and 60 $\mathrm{mm}$ diameter and length respectively. Wick sample compacted by sintering process. Sintering temperature was 950 degree for 60 second. The porosity and microstructure of wick sample tested by SEM and the results were analyzed by Image-J software to get particle shape, pore size, and porosity. The porosity will comparing with the result of capillary pumping tested. Furthermore, capillary pumping performance, porosity and microstructure of molecular sieve and hybrid molecular sieve-Cu examined by comparing with biomaterial wick. The result show that molecular sieve can be considered as a wick material.
\end{abstract}

Keywords—wick; molecular sieve; porosity; microstructure

\section{INTRODUCTION}

Wick was an important component of heat pipe. wick created capillary force that pulling back the condensed liquid from the condenser to the evaporation without external force. Wick was the main criteria in evaluating heat pipe performance [1-4]. From the researches had been conducted, the desired characteristics of the wick are high capillary driving force, low hydraulic resistance (i.e. permeability) and low thermal conductivity. Capillary driving force and permeability achieved with high porosity and improve microstructure [4-5]. In heat pipe heat transfer start at the evaporator, because heat fluxes inputted in the evaporator. The heat flows through the pipe wall by conduction and natural convection and contact with the working fluids. As the heat flux increases, the working fluids at the wall becomes superheated, and bubble formation appears inside the wicks. Subsequently, the bubble becomes the carrier in the form of vapour to transport energy through latent heat of vaporization. A driving force is created due to the difference of vapour pressure between the evaporator and the condenser, pushing the mass transfer of vapour to the condenser releasing latent heat. The condensed fluid will then flow back to the evaporator by capillary forces generated from surface tension of the wick thus repeating the above cycle passively. The heat transfer mechanism describe in Fig. 1. In this research wick will be developed with natural material that is molecular sieve.

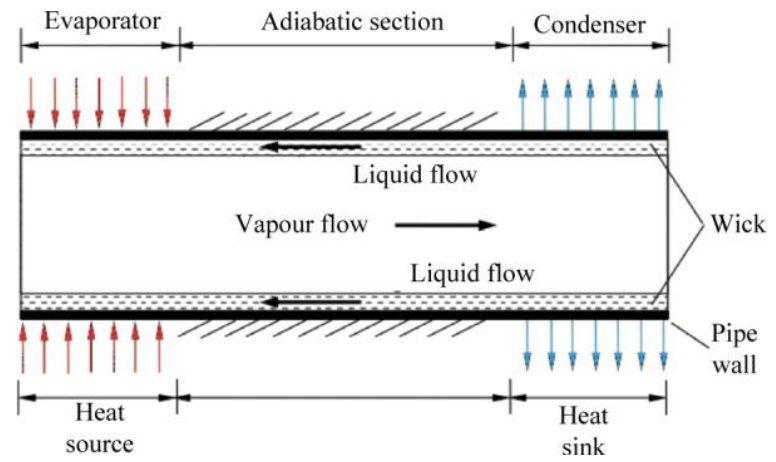

Fig. 1 heat transfer mechanism [1]

Extensive sedimentary deposits of micro-crystalline molecular sieves, e.g. formed by alteration of volcanic tuff. The synthesis of molecular sieves is generally accomplished under hydrothermal conditions. A great variety of application of molecular sieve are adsorption, ion exchange, catalyst.

Porosity is defined as the ratio between volumes the space between the powder in the form of pore (the space between the powders which is always filled with fluid such as air, oil or natural gas) to powder volume overall. Molecular sieve is composed of pore which is evenly distributed with homogenic 
sizes. Porosity and pore size can be analyzed from the micrographic appearance of SEM by using software Image-J.

The main goal of this research was to investigate porosity and microstructure wick sample that use molecular sieve as a material.

\section{EXPERIMENT}

\section{A. Sample preparation}

To investigate the porosity and microstructure of molecular sieve heat pipe, porous media must generated. First step was crushed the molecular sieve to get smaller size. Then characterize the particle size into $100 \mu \mathrm{m}$ and $200 \mu \mathrm{m}$. The dry molecular sieve powder added to the binding material. Binding material was made from tapioca flour and water. Molecular sieve and binding (slurry) were shaped in the form of copper pipe $25.4 \mathrm{~mm}$ and $60 \mathrm{~mm}$ diameter and length respectively. The compaction process was carried out with the sintering process. Sintering temperature was 950 degree for 1 hour.

\section{B. Set up experiment}

Molecular sieve wick sample microstructure is characterized using SEM. The results of sample micrography were analyzed by using Image-J software to find out pore size of the sample. Micrographic analysis SEM samples include the following three stages: image preparation, image threeshold and image analysis. From Image-J, the total sample surface area data is obtained analyzed (AT) and total pore area analyzed from sample. Then porosity can be calculated by the equation:

$$
\varphi=\frac{A_{T}}{A_{T P}} \times 100 \%
$$

\section{RESULTS AND DISCUSSION}

From SEM obtained the picture as describe Fig. 2., and the Image-J analysis describe in Table 1.

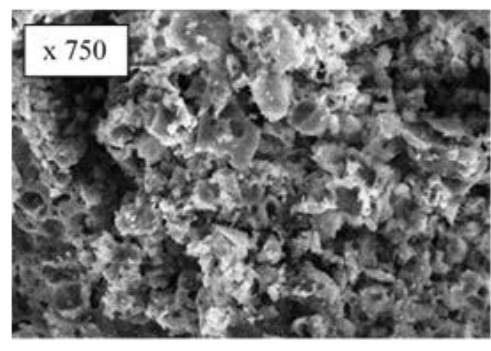

Fig 2. SEM image of sintered powder molecular sieve

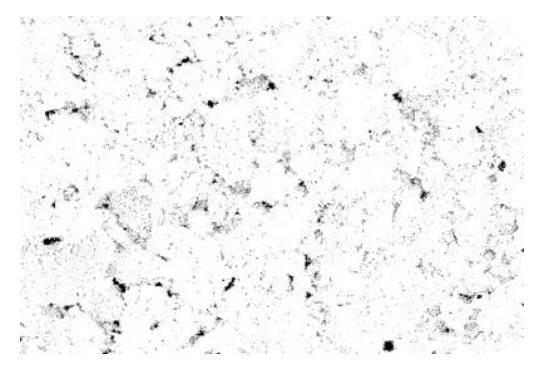

Fig. 3. Image threshold process.

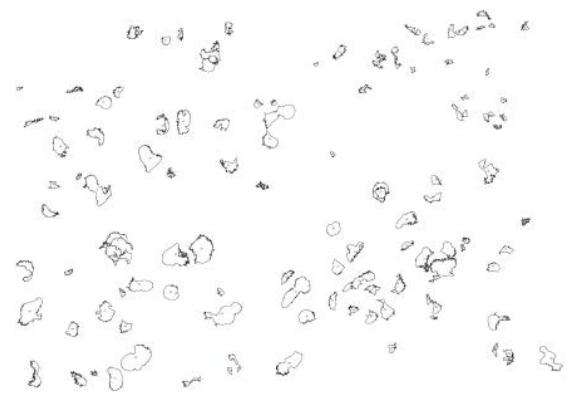

Fig. 4. Image analyzed.

The micro-morphologies (SEM) and the pore size distribution studied by using the image analysis method of those molecular sieve samples. Table 1 . shows the porosity of the sample. The increasing porosities of the porous wicks will increase the capillary pumping performance.

TABLE 1. POROSITY OF MOLECULAR SIEVE WICK

\begin{tabular}{|c|c|c|c|}
\hline Sample & Count & Total Area & Porosity (c) \% \\
\hline 1 & 115 & 1124.295 & 0.10 \\
\hline 2 & 236 & 1104.212 & 0.21 \\
\hline
\end{tabular}

Porosity of the molecular sieve wick were in range $0.1<\varepsilon \leq 1$. This range this range is the allowable range as the porous media.

\section{CONCLUSION}

Porosity is one of the requirements that must be possessed as porous media. Porosity will affect the porosity of the capillary performance, the greater the porosity generate the higher heat transfer of the porous media.

\section{ACKNOWLEDGMENT}

The authors would like to acknowledge Udayana University and AHTRG Laboratory University of Indonesia. The authors greatly appreciate the support and helpful suggestions.

\section{REFERENCES}

[1] Q. Wang, , J. Hong, Y. Yan, "Biomimetic Capillary Inspired Heat Pipe Wicks,”J. of Bio. Eng., vol : 11, pp. 469-480, 2014.

[2] D. Reay, R. McGlen, and P. Kew, Heat Pipes: Theory, design and applications, 5th ed., Butterworth-Heinemann, 2006, pp. 1-7.

[3] L. Jiang, Y.Tang, W. Zhou, L. Jiang, T. Xiao, Y. Li, J. Gao, "Design and fabrication of sintered wick for miniature cylindrical heat pipe," Trans. Nonfer. Met. Soc. China, vol : 24, pp. 292-301, 2014.

[4] J. Choi, W. San, W. Zhang, Y. Yuan, Y. Lee, "Experimental investigation on sintered porous wicks for miniature loop," Ex.Therm. and F. Sci., vol. 51, pp. 271-278, 2013.

[5] D. Deng, Y.Tang, G. Huang, L. Lu, D.Yuan, "Characterization of capillary performance of composite wicks for two-phase heat transfer devices,” Int. J. of Heat and Mass Trans., vol. 56, pp. 283-293, 2013.

[6] D.P. Roelofsen, Molecular Sieve Zeolite - Properties and Applications in Organic Synthesis, Anal. Chem. 43, 631 (1971). 